\title{
Diversity and Abundance of Anopheles (Diptera: Culicidae) Species Complex in some Selected Settlements in Ogbomoso Local Government Area of Oyo-State, Nigeria
}

\author{
Oluwasogo $\mathrm{AO}^{1,2^{*}}$, Adeyemi MA ${ }^{3}$, Gabriel $\mathbf{S}^{1}$, Kabir $\mathrm{OO}^{4}$, Owolabi AA ${ }^{3}$ and Henry $\mathbf{O S}^{1,3}$ \\ ${ }^{1}$ School of Allied Health and Environmental Sciences, College of Pure and Applied Sciences, Kwara State University, Nigeria \\ ${ }^{2}$ Centre for Ecological and Environmental Research Management Studies, Kwara State University, Nigeria \\ ${ }^{3}$ Department of Bio-Sciences and Biotechnology, Kwara State University, Nigeria \\ ${ }^{4}$ Department of Statistics and Mathematical Sciences, Kwara State University, Nigeria
}

"Corresponding author: Oluwasogo AO, Centre for Ecological and Environmental Research Management Studies, Kwara State University, Nigeria, Tel: 234-703603-9078; E-mail: olalubisogo@gmail.com

Received date: Apr 04, 2016; Accepted date: June 27, 2016; Published date: June 30, 2016

Copyright: (c) 2016 Oluwasogo AO, et al. This is an open-access article distributed under the terms of the Creative Commons Attribution License, which permits unrestricted use, distribution, and reproduction in any medium, provided the original author and source are credited.

\begin{abstract}
Background: It is part of efforts of every passionate government in Africa to reduce, if not eliminate morbidity and mortality due to malaria being transmitted by female anopheles mosquito. Part of this struggle is the malaria indicator survey annually conducted by the Federal Bureau of Statistics (FBS) in Nigeria. It therefore important to communicate community based investigation and communication of entomological data vital for malaria control using appropriate statistical tools. This study generally aims to investigate seasonal abundance of Anopheles mosquito species and their compositions in some selected human settlements. The specific objective is to determine which particular specie of such Anopheles mosquitoes are most abundant and which of the human settlements requires most intervention due to high prevalence of such Anopheles.
\end{abstract}

Methods: Mosquito collection was made once per week indoor between 5:30hr to 7:00hr and 20:00hr to 22:00hr in rooms for twelve months using insecticide spray technique. Adult Mosquitoes from the knock down effect were collected and identified to species and species complex level using keys described by Gillett, Gillies and Coetzee. Two sample test of proportion was adopted to test for significant difference between species occurrence. The Friedman rank sum test was utilized to determine whether or not there exists a statistically detectable difference in abundance of the four species of anopheles mosquitoes in the seven study wards and whether the seven study ward significantly differ in their composition of the four species of anopheles complex.

Results: At $5 \%$ significance level $(\alpha=0.05)$, the test revealed with $p$-values 0.0001 and 0.0005 that there is statistically detectable difference among median abundance of the four Anopheles species. An. gambiae s.I. had the highest median (3006) abundance, followed by An. arabiensis (834.5), An. rufipes (608) and An. funestus (471), respectively. However, Akata ward had the largest median composition (812) of the mosquito species followed by Lagbedu ward (786). Alapata ward rank third in terms of median abundance (739.5). Ibapon and llogbo wards had approximately the same median Anopheles composition of 714 out of the total of 35,974 . Arowomole ward had the least median composition (698). However, most mosquito species (6822) was collected in October and the least (252) in February.

Conclusion: Identifying human activities and practices that promote mosquito breeding by communities themselves, identifying and selecting culturally appropriate mosquito control techniques, and the initiation of actions aimed at controlling mosquito abundance are among community directed and self-reliant coping strategies envisaged. Among such includes Long-Lasting Insecticide Treated Bednets, (LLITNs) alongside with Indoor residual spray and most importantly the practice of Larval Source Management (LSM) (Larviciding) in the study areas.

Keywords: Mosquito; Anopheles complex; Incidence; Coping strategies

\section{Introduction}

In most parts of the tropics, Malaria is life-threatening disease transmitted through the bite of a female Anopheles mosquito. Although recent estimates suggest that malaria mortality rates decreased by an impressive 47\% between 2000 and 2013 globally, and by $54 \%$ in the World Health Organization's (WHO) African Region, malaria remains a major public health problem in a number of countries [1]. Majority of the world's population live in areas at risk of vector borne diseases, most of which are spread through mosquitoes [2-5].

Mosquitoes are important vectors of most deadly diseases such as malaria, lymphatic filariasis, dengue and yellow fever and many others in Nigeria [6,7]. The continued transmission of the mosquito bornediseases is perhaps due to seasonal alternation of cold and warm climates and the vast larval habitats available that ensure prolific and continuous breeding of the vectors [8,9]. Agricultural occupational 
Citation: Oluwasogo AO, Adeyemi MA, Gabriel S, Kabir OO, Owolabi AA, et al. (2016) Diversity and Abundance of Anopheles (Diptera: Culicidae) Species Complex in some Selected Settlements in Ogbomoso Local Government Area of Oyo-State, Nigeria. Malaria Contr Elimination 5: 146. doi:10.4172/2470-6965/1000146

Page 2 of 6

practices such as the use of irrigation, the use of ponds for fish, rice farming and the storage of water in tanks for domestic and livestock provide suitable breeding grounds for anthropophylic mosquitoes [10-12].

The most common anthropophylic mosquito in Nigeria which causes much of the morbidity and mortality associated with malaria is the Anopheles mosquito [12-15]. However, not much is known about species composition, distribution and abundance of Anopheles species in Ogbomoso, Oyo-state, Nigeria. This study presents the impact of Anopheles mosquito species on seven human settlements in Ogbomoso South, Local Government Area Council.

\section{Materials and Methods}

\section{Study area}

The study was conducted in seven wards (Lagbedu, Arowomole, Ibapon, Alapata, Ilogbo, Akata and Oke-Ola) in Ogbomoso South Local Government Area Council, Oyo, South-western Nigeria. The town is situated on Longitude $4.25^{\circ} \mathrm{E}$ and Latitude $8.13^{\circ} \mathrm{N}$. Ogbomoso has a typical tropical climate with a mean annual temperature of $26.1^{\circ} \mathrm{C}$, relative humidity of $78 \%$ and an average rainfall of $1217 \mathrm{~mm}$. It has population density of about 150,000 with area covers of 10,500 square meters surrounded with streams and rivers. The study area is known for human activities such as farming, hunting, fishing and damming, dyeing, trading and construction works (Figure 1).

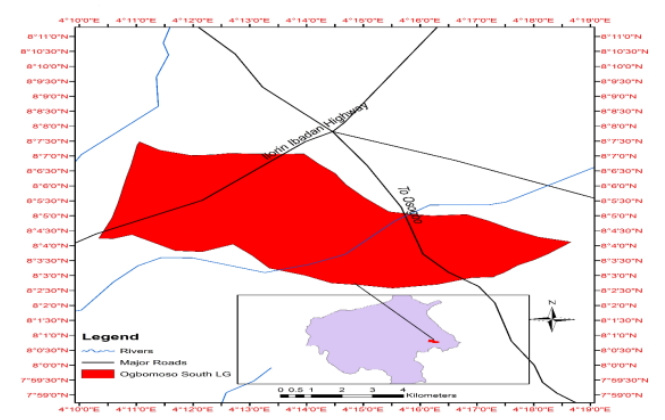

Figure 1: Ogbomoso South Local Government (Inset) Oyo State, Nigeria.

\section{Collection of adult indoor resting mosquitoes}

Mosquitoes' captures were carried out from randomly selected households from seven villages at the study area. The collection was made once per week indoor between 5:30 hr and 7:00 hr and at night between 20:00 hr and 22:00 hr in rooms in each of the selected houses at the study locations, using insecticide spray technique. White sheets were spread on the floor and all the windows and doors were closed. Mosquitoes from the knock down effect were collected and transferred into small plastic containers with cover containing silica gel and labelled. The date, place and time of collection were also recorded. The collection was carried out for twelve months between August 2014 and July 2015. Captured adult mosquitoes were identified to species and species complex level using keys described by Gillett, Gillies and Coetzee $[16,17]$.

\section{Ethical considerations}

All aspects of the study were approved by Kwara State University Research Committee and Ethical Review Board. Verbal and written Informed consent was obtained from the individuals that partook in mosquito collection. They were assured of voluntary participation, confidentiality of their roles and the opportunity to withdraw at any time without prejudice.

\section{Statistical Data Analysis}

Due to the nature and structure of the data sets obtained from the field and the aim of the study to determine whether, on average, there exists a statistically detectable difference in abundance of the four species of anopheles mosquitoes in the seven study wards and whether the seven study ward significantly differ in their composition of the four species of anopheles complex, the non-parametric equivalent of the two-way analysis of variance (ANOVA) called the Friedman test [18] was conducted. Our choice of this statistical procedure is based on the fact that the data comprises unreplicated complete block designs structure with exactly one observation for each experimental factor level (i.e. anopheles species) for each combination of group variable levels (i.e. study wards) and that because observations are counts, the normality assumption may be violated. The Friedman test is known to give reliable results whether or not normality assumption holds.

The analysis was done using the stats library of the R software for statistical computing and graphics [19] version 3.3.2. via the $\mathrm{R}$ studio (RStudio, Inc.) integrated development environment (IDE) (Table 1).

\begin{tabular}{|c|c|c|c|c|c|c|c|c|c|c|c|c|c|c|}
\hline Ward/Month & Aug & Sept & Oct & Nov & Dec & Jan & Feb & Mar & Apr & May & June & July & Total & $\%$ \\
\hline Lagbedu & 685 & 856 & 1027 & 799 & 458 & 57 & 42 & 145 & 159 & 173 & 479 & 572 & 5452 & 15.2 \\
\hline Arowomole & 697 & 744 & 948 & 755 & 357 & 50 & 32 & 133 & 147 & 156 & 348 & 502 & 4869 & 13.5 \\
\hline Ibapon & 701 & 885 & 991 & 759 & 230 & 44 & 29 & 140 & 135 & 167 & 355 & 546 & 4982 & 13.8 \\
\hline Alapata & 732 & 946 & 1002 & 680 & 447 & 51 & 38 & 100 & 145 & 133 & 360 & 511 & 5145 & 14.3 \\
\hline llogbo & 854 & 760 & 884 & 669 & 410 & 46 & 34 & 128 & 134 & 142 & 368 & 522 & 4951 & 13.8 \\
\hline Akata & 905 & 892 & 1012 & 792 & 457 & 55 & 41 & 143 & 157 & 171 & 465 & 574 & 5664 & 15.7 \\
\hline Oke-ola & 657 & 900 & 958 & 768 & 354 & 49 & 36 & 132 & 134 & 122 & 345 & 456 & 4911 & 13.7 \\
\hline Total \% & 5231 & 598317 & 682219 & 522215 & 27137.5 & 3520.9 & 2520.7 & 9212.6 & 10112.8 & 10642.9 & 27207.5 & 368310 & $3.6 \mathrm{E}+07$ & 100 \\
\hline
\end{tabular}


Citation: Oluwasogo AO, Adeyemi MA, Gabriel S, Kabir OO, Owolabi AA, et al. (2016) Diversity and Abundance of Anopheles (Diptera: Culicidae) Species Complex in some Selected Settlements in Ogbomoso Local Government Area of Oyo-State, Nigeria. Malaria Contr Elimination 5: 146. doi:10.4172/2470-6965/1000146

\begin{tabular}{|l|l|l|l|l|l|l|l|l|l|l|l|}
\hline 14.5 & & & & & & & & & & \\
5231 & & & & & & & & & & & \\
14.5 & & & & & & & & & & \\
523115 & & & & & & & & & \\
\hline
\end{tabular}

Table 1: Adult mosquito species collected indoors at the study area.

\section{Data description and results summary}

In Table 1, abundance and seasonal distribution of adult mosquito species collected from the households are summarized. Most mosquito species $6822(18.96 \%)$ was collected in October and the least 252 $(0.7 \%)$ in February. Figure 2 furthers summarizes these results.

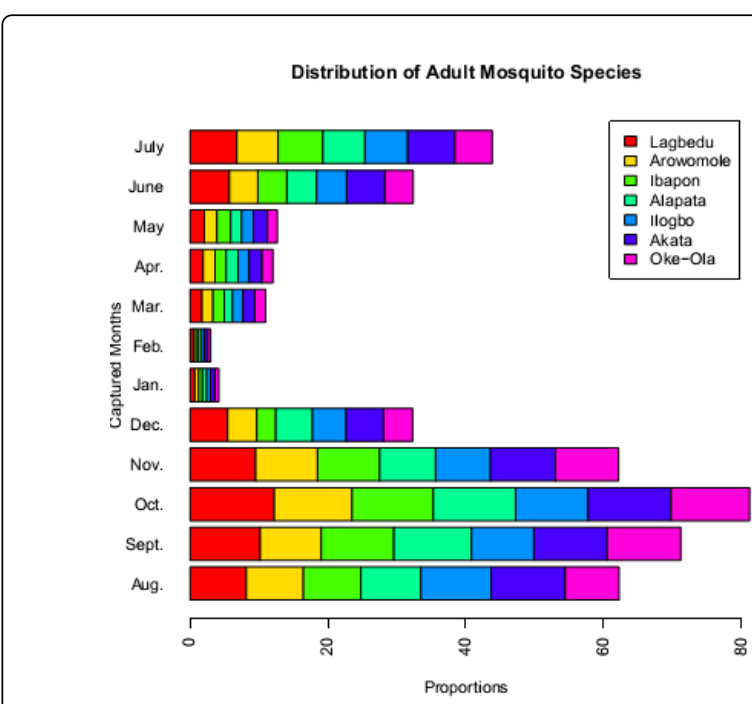

Figure 2: Stacked Bar Chart showing Seasonal Abundance of Indoor resting adult mosquito species across study areas.

The result of the study revealed that, of the 35,974 mosquito species sample obtained during the study, Anopheles (An. gambiae s.l., An. funestus, and An. Arabiensis and An. rufipes) constituted the predominant species $35542(98.79 \%)$ and other species the least 432 (1.21\%) (Table 2).

\begin{tabular}{|l|l|l|}
\hline Mosquito Species & $\begin{array}{l}\text { No of Adults } \\
\text { Collected }\end{array}$ & $\%$ Occurrence \\
\hline Anopheles mosquito complex & 35542 & 98.79 \\
\hline Others & 432 & 1.21 \\
\hline Total & 35974 & 100 \\
\hline
\end{tabular}

Source: Field Survey, 2015

Table 2: Mosquito Species Occurrence at the Study Area.

We investigated whether or not proportion of anopheles complex occurrence is significantly greater than that of other species in the study wards using the two-sample test of proportion summarized in Table 3.

\begin{tabular}{|l|l|l|l|l|l|}
\hline Data & $\begin{array}{l}\text { X- } \\
\text { square }\end{array}$ & $\begin{array}{l}\text { Degree } \\
\text { of } \\
\text { freedom }\end{array}$ & P-value & \multicolumn{2}{|l|}{$\begin{array}{l}\text { 95 percent confidence } \\
\text { interval }\end{array}$} \\
\cline { 3 - 6 } & & & $\begin{array}{l}\text { Lower } \\
\text { Bound }\end{array}$ & $\begin{array}{l}\text { Upper } \\
\text { Bound }\end{array}$ \\
\hline $\begin{array}{l}\text { Specie } \\
\text { Occurrence }\end{array}$ & 68529.6 & 1 & $2.20 \mathrm{E}-1$ & 0.9746 & 1 \\
\hline
\end{tabular}

Table 3: 2-Sample Test for Equality of Proportions with Continuity Correction.

The small p-value 2.2e-16 rejects the null hypothesis of less or equal proportions of mosquito species occurrence in the study wards. This implies that anopheles complex species are truly statistically more than other species at $95 \%(\alpha=0.05)$ significance level. This inference is also evident in Figure 3.

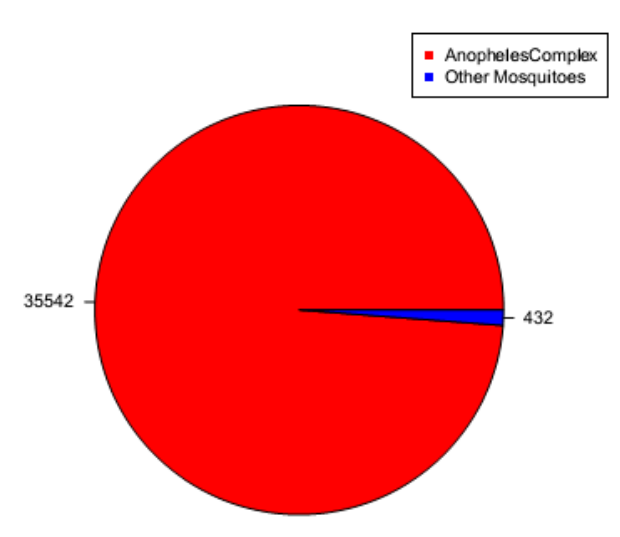

Figure 3: Mosquito specie occurrence at the study area.

In Table 4, the most predominant according to frequency counts $(21,787)$ of the Anopheles species encountered during the study was Anopheles gambiae (61.3\%). Anopheles arabiensis,Anopheles rufipesand Anopheles funestusconstituted 16.7\%, 12.4\% and 9.6\%, respectively.

\begin{tabular}{|l|l|l|}
\hline Anopheles mosquito spp & No of adult collected & \% Occurrence \\
\hline An. gambiae s.l. & 21787 & 61.3 \\
\hline An. funestus & 3412 & 9.6 \\
\hline An. rufipes & 4407 & 12.4 \\
\hline An. arabiensis & 5936 & 16.7 \\
\hline Total & 35542 & 100 \\
\hline
\end{tabular}


Citation: Oluwasogo AO, Adeyemi MA, Gabriel S, Kabir OO, Owolabi AA, et al. (2016) Diversity and Abundance of Anopheles (Diptera: Culicidae) Species Complex in some Selected Settlements in Ogbomoso Local Government Area of Oyo-State, Nigeria. Malaria Contr Elimination 5: 146. doi:10.4172/2470-6965/1000146

Page 4 of 6

Source: Field Survey, 2015

Table 4: Adult anopheles species collected at the study area.

Table 5, presents the incidence of Anopheles mosquito species within seven human settlements including Lagbedu, Arowomole, Ibapon, Alapata, Ilogbo, Akata, and Oke-Ola wards at Ogbomoso. Of a total of 35542 species encountered, Akata had most (5581) prevalent mosquito species at the study area. Lagbedu ward ranks with 5403 (15.2\%) anopheles species, $5083(14.3 \%)$ were recorded from Alapata ward while the least 4798 (13.5\%) were recorded from Arowomole ward, respectively. Ibapon and Ilogo wards have equal (4904) distribution of anopheles species.

\begin{tabular}{|l|l|l|l|l|l|l|}
\hline $\begin{array}{l}\text { Study } \\
\text { wards }\end{array}$ & $\begin{array}{l}\text { An. } \\
\text { gambiae. } \\
\text { s.I }\end{array}$ & $\begin{array}{l}\text { An. } \\
\text { funestus }\end{array}$ & $\begin{array}{l}\text { An. } \\
\text { rufipes }\end{array}$ & $\begin{array}{l}\text { An. } \\
\text { arabiensis }\end{array}$ & Total & $\%$ \\
\hline Lagbedu & 3312 & 519 & 670 & 902 & 5403 & 15.2 \\
\hline Arowomole & 2941 & 461 & 595 & 801 & 4798 & 13.5 \\
\hline Ibapon & 3006 & 470 & 608 & 820 & 4904 & 13.8 \\
\hline Alapata & 3116 & 488 & 630 & 849 & 5083 & 14.3 \\
\hline Ilogbo & 3006 & 471 & 608 & 819 & 4904 & 13.8 \\
\hline Akata & 3421 & 536 & 692 & 932 & 5581 & 15.7 \\
\hline Oke-Ola & 2985 & 467 & 604 & 813 & 4869 & 13.7 \\
\hline Aggregate & 21787 & 3412 & 4407 & 5936 & 35542 & 100 \\
\hline Source: Field Survey, 2015 & & & & \\
\hline
\end{tabular}

Table 5: Anopheles mosquito species distribution per settlement.

\section{Friedman rank sum test of significance for anopheles specie abundance}

In order to determine whether there exist a statistically detectable difference in abundance of the four species of Anopheles mosquitoes in the study area and to investigate whether on average, the seven study wards differ significantly in terms of their composition of the four Anopheles species, we conducted the Friedman rank sum test on results presented (Tables 6 and 7).

\begin{tabular}{|c|c|c|c|c|}
\hline Source & $\begin{array}{l}\text { Friedman } \quad X- \\
\text { squared }\end{array}$ & $\begin{array}{l}\mathbf{D} \\
\mathbf{F}\end{array}$ & $\begin{array}{l}P \text { - } \\
\text { value }\end{array}$ & Decision \\
\hline $\begin{array}{l}\text { Anopheles } \\
\text { Species }\end{array}$ & 21 & 3 & 0.0001 & $\begin{array}{l}\text { Reject null of no statistical } \\
\text { difference }\end{array}$ \\
\hline DF: Degree & eedom & & & \\
\hline
\end{tabular}

Table 6: Test of significance for difference in anopheles species abundance.

Since the p-value 0.0001 for the four mosquito species is smaller than 0.05 , we reject the null hypothesis that: on average, all the four species of Anopheles mosquito have equal abundance across the seven study areas. This means that there is statistically detectable difference between abundance of the four species. This inference is further revealed by the box and whisker plot in Figure 4 where An. gambiae s.l. (3006) had the highest median abundance. Next in median abundance across the seven study wards is An. arabiensis (834.5), followed by $A n$. rufipes (608) and $A n$. funestus (471) in the order summarized in what follows: An.gambiae s.l.>An.arabiensis $>$ An.rufipes $>$ An.funestus.

\begin{tabular}{|l|l|l|l|}
\hline Source & $\begin{array}{l}\text { Friedman } \\
\text { squared }\end{array}$ & DF & P-value \\
\hline Anopheles Species & 23.784 & 6 & 0.0005 \\
\hline DF: Degree of Freedom & & \\
\hline
\end{tabular}

Table 7: Test of Significance for difference in study word composition of anopheles species.

Also, p-value 0.0005 rejects the null hypothesis that on average, the study wards are the same in terms of mosquito composition. This implies that all the seven human settlements differ in terms of composition of Anopheles mosquitoes.

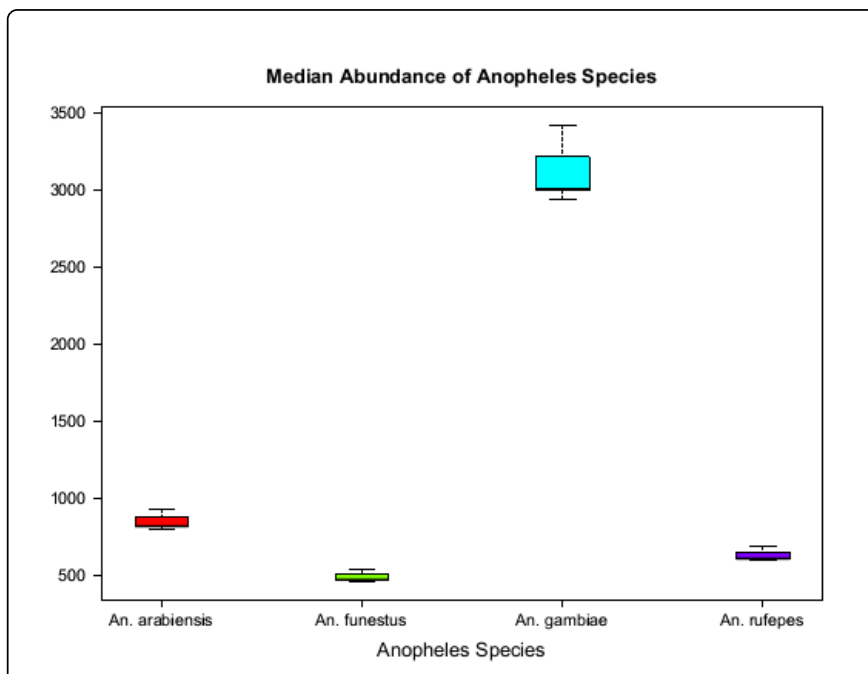

Figure 4: Median Abundance of Anopheles Mosquito Species.

Evidence in Figure 5 further reveals the inference from (Table 7). Although all the seven study wards have appreciable spread of composition of the four An. species, it is still crystal clear that Akata had the largest median composition of the mosquito species followed by Lagbedu ward. All other wards have approximately the same median composition of the species.

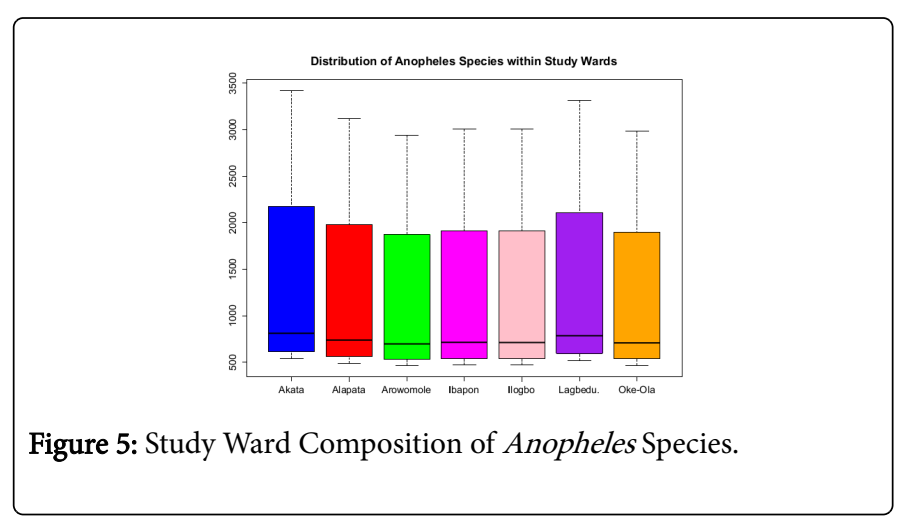




\section{Discussion of Results}

From the foregoing, data evidences revealed that based on seasonal abundance, most mosquito species (6822) were collected in October and the least (252) in February. Of the 35,974 mosquito species sample obtained during the study, An. gambiae s.l constituted the predominant species (3006 out of 35542) and the least predominant species (471 out of 35542) in the study area is An. funestus. This inference is further evident in the rejection of the null hypothesis that: on average, all the four species of Anopheles mosquito have equal abundance across the seven study areas with p-value 0.0001 reported by the Friedman Rank Sum Test (FRST).

Similar results in Gimba and Idris reported that An. gambiae s.I constituted 942 (82.70\%), An. arabiensis with 91 (7.99\%), followed by An. rufipes 62 (5.62\%), and An. funestus the least population $42(3.69 \%)$ a total of 2,929 collected. Our study follows similar trend with more sample $(35,974)$. In the two studies, An. gambiae has the highest abundance. This data are expected to assist integrated vector control programmer to devote more control efforts to elimination of An.

With p-value $2.2 \mathrm{e}-16$ of the two-sample test of proportion revealed that there is enough data evidence to reject the null hypothesis of "less or equal proportions of mosquito species occurrence" in the study wards. This implies that anopheles complex species are truly statistically more than other species at $5 \%$ significance level. However, of a total of 35542 species encountered, Akata ward had most (5581) prevalent mosquito species at the study area while the least (4798) were recorded from Arowomole ward, respectively. This inference is based on the fact that at $5 \%$ significance level, p-value 0.0005 reported by the FRST for testing the null hypothesis that "on average, the study wards are the same in terms of mosquito composition" revealed that all the seven human settlements differ in terms of composition of Anopheles mosquitoes.

\section{Conclusion}

Following results presented in this study, we can infer that abundance of the four species is not the same in the study areas. Specifically, identifying human activities and practices that promote mosquito breeding by communities themselves, identifying and selecting culturally appropriate mosquito control techniques and adoption of ownership of such interventions and the initiation of actions aimed at controlling mosquito abundance are among community directed and self-reliant coping strategies such as LongLasting Insecticide Treated Bednets, (LLITNs) alongside with Indoor residual spray and most importantly the practice of Larval Source Management (LSM) (Larviciding) in the study areas.

\section{Recommendations}

This data should assist malaria programmers to plan and implement interventions to reduce risk of malaria infections in the rural endemic communities. Multiple interventions are recommended for tackling the challenges identified in this study. The use of community organization and development is one of the interventions that hold great promise. It should entail enhancing the capacity of community-directed interventions aimed at controlling Anopheles in rural communities in Ogbomoso. The critical steps or approaches may include the following: identifying and alleviating human activities and practices that promote mosquito breeding by communities themselves; identifying and selecting culturally appropriate mosquito control techniques; and the initiation of actions aimed at controlling mosquito abundance in the spirit of self-reliance and self-determination. The rationale usage and practice of larvicides to eliminate larva stage of the mosquito in identified fixed habitat should be highly encouraged.

\section{Acknowledgement}

We are most grateful to the inhabitants of the study communities for granting us undeniable access to their dwelling places.

\section{Funding Information}

Secondary project: Supported by Centre for Sponsored Project, Conditional Education Trust Fund Research Grant, Kwara State University, Malete, Nigeria (Grant No. ASU/CSP/062215/VOL3/TETF/ 0030).

\section{References}

1. Abdoulaye $\mathrm{AD}$, Amelia WM, Dinkorma $\mathrm{O}$, Bakary $\mathrm{F}$, Issaka $\mathrm{S}$, et al. (2016) Gametocyte clearance dynamics following oral artesunate treatment of uncomplicated falciparum malaria in Malian children. Parasite 23:3.

2. Townson H, Nathan MB, Zaim M, Guillet P, Manga L, et al. (2005) Exploiting the potential of vector control for disease prevention. Bull W Health Organ 83: 942-947.

3. Aina SA, Banjo AD, Lawal OA, Jonathan K (2009) Efficacy of some plant extracts on Anopheles gambiae mosquito larvae. Acad J Entomol 2: 31-35.

4. Ilahi I, Suleman M (2013) Species composition and relative abundance of mosquitoes in Swat, Pakistan. Int J Innov App Stud 2: 454-463.

5. Guruprasad NM, Jalali SK, Puttaraju HP (2014) Wolbachia-a foe for mosquitoes. Asian Pac J Trop Dis 4: 78-81.

6. Mbanugo JI, Okpalononuju CN (2003) Surveillance of Mosquito Vectors in some habitats of Awka Metropolis, Anambra, Nigeria. Nigeria J Parasitol 24: 185-190.

7. Ajao AM, Adeleke MA (2014) Species composition and seasonal abundance of mosquito vectors in rice growing community in Kwara State, North Central, Nigeria. Mun Ent Zool 9: 838-841.

8. Amusan AAS, Mafiana CF, Idowu AB, Oke OA (2003) A survey of adult mosquitoes in the hostels of the University of Agriculture, Abeokuta, Ogun State Nigeria. Nigeria J Parasitol 24: 167-172.

9. Anthony K, Andrew M, Pia M, Soma E, Sachs J, et al. (2005) A global index representing the stability of malaria transmission. Am J Trop Med 70: 486-498

10. Okogun GRA, Anosike JC, Okere AN, Nwoke BED (2005) Ecology of mosquitoes of Midwestern Nigeria. J Vector Borne Dis 42: 1-8.

11. Oduola AO, Awe OO (2006) Behavioural biting preference of Culex quinquefasciatus in human host in Lagos metropolis, Nigeria. J Vector Borne Dis 43: 16-20.

12. Adeleke MA, Adebimpe WO, Hassan AO, Oladejo SO, Olaoye I, et al. (2013) Larval habitats of mosquito fauna in Osogbo metropolis Southwestern Nigeria. Asian Pac J Trop 3: 673-677.

13. Oladimeji O, Grace OT, Frederick OO, Musibau AT (2010) Malaria knowledge and agricultural practices that promote mosquito breeding in two rural farming communities in Oyo State, Nigeria. Malaria J 9: 91.

14. Rubio A, Bellocq MI, Vezzani D (2012) Community structure of artificial container-breeding flies (Insecta: Diptera) in relation to the urbanization level. Landscape Urban Plan 105: 288-295.

15. Abiodun O, Adedayo O, Kehinde P, Adeyemi A (2014) Community knowledge and practices as regards malaria in Ilorin City: implications for the elimination plan of the National Malaria Elimination Program. Asian Pac J Trop Dis 4: S583-S589. 
Citation: Oluwasogo AO, Adeyemi MA, Gabriel S, Kabir OO, Owolabi AA, et al. (2016) Diversity and Abundance of Anopheles (Diptera: Culicidae) Species Complex in some Selected Settlements in Ogbomoso Local Government Area of Oyo-State, Nigeria. Malaria Contr Elimination 5: 146. doi:10.4172/2470-6965/1000146

Page 6 of 6

16. Gilles MT, Coetzee M (1987) A supplement to the Anophelinae of Africa south of the Sahara (Afro Tropical Region). Publ South Afr Inst Med Res 55: 1-143.

17. Gillet JD (1972) Common African Mosquitoes and their medical importance (with colour illustrations). William Heinemann Medical Books Ltd London pp 236.
18. Myles H, Douglas AW (1973) Nonparametric Statistical Methods. New York John Wiley \& Sons 139-146.

19. R Core Team (2015) A language and environment for statistical computing. R Foundation for Statistical Computing, Vienna, Austria. 